\title{
The Effects of Exercise Intensity on p-NR2B Expression in Cerebral Ischemic Rats
}

\author{
Anjing Zhang, Yulong Bai, Yongshan Hu, Feng Zhang, Yi Wu, Yang Wang, \\ Ping Zheng, Qiang He
}

\begin{abstract}
Background: The current study explored the effects of treadmill exercise intensity on functional recovery and hippocampal phospho-NR2B (p-NR2B) expression in cerebral ischemic rats, induced by permanent middle cerebral artery occlusion (MCAO) surgery. Method: Adult male Sprague-Dawley rats were randomly divided into four groups, including sham, no exercise (NE), low intensity training (LIT, $v=15 \mathrm{~m} / \mathrm{min}$ ), and moderate intensity training groups (MIT, $\mathrm{v}=20 \mathrm{~m} / \mathrm{min}$ ). At different time points, the hippocampal expressions of p-NR2B and total NR2B were examined. In addition, neurological deficit score (NDS), body weight, and 2,3,5-triphenyltetrazolium chloride (TTC) staining were used to evaluate brain infarct volume as assessments of post-stroke functional recovery. In order to investigate the effect of exercise on survival, the mortality rate was also recorded. Results: The results showed that treadmill exercise significantly decreased hippocampal expression of p-NR2B but didn't change the total NR2B, compared to the NE group on the 3rd, 7th, and 14th days following MCAO surgery. The effect on changes in p-NR2B levels, body weight, and brain infarct volume were more significant in the LIT compared to the MIT group. Discussion and Conclusion: The current findings demonstrate that physical exercise can produce neuroprotective effects, in part by down-regulating p-NR2B expression. Furthermore, the appropriate intensity of physical exercise is critical for post-stroke rehabilitation.
\end{abstract}

RÉSUMÉ: Les effets de l'intensité de l'exercice sur l'expression de p-NR2B dans l'ischémie cérébrale chez le rat. Contexte : Cette étude explore les effets de l'intensité de l'exercice sur un tapis roulant sur la récupération fonctionnelle et sur l'expression du phospho-NR2B (p-NR2B) dans l'hippocampe dans l'ischémie cérébrale induite par l'occlusion chirurgicale permanente de l'artère cérébrale moyenne (OACM) chez le rat. Méthode : Des rats Sprague-Dawley mâles adultes ont été répartis au hasard en 4 groupes. Chacun des groupes recevait soit une intervention factice, pas d'exercice (PE), entraînement de faible intensité (EFI, $\mathrm{v}=15 \mathrm{~m} / \mathrm{min}$ ), ou entraînement d'intensité modérée (EIM, v = 20 m/min). L'expression du p-NR2B dans l'hippocampe et le NR2B total ont été mesurés à différents moments. De plus, nous avons utilisé le score de déficit neurologique (SDN), le poids corporel et la coloration par le chlorure de 2,3,5-triphényltétrazolium (CTT) pour évaluer le volume de l'infarctus cérébral comme mesures de la récupération fonctionnelle après un accident vasculaire cérébral (AVC). Nous avons également déterminé le taux de mortalité afin d'examiner l'effet de l'exercice sur la survie. Résultats : Les résultats démontrent que l'exercice sur tapis roulant diminuait significativement l'expression du p-NR2B dans l'hippocampe, mais ne changeait pas le NR2B total, comparé au groupe PE, 3, 7 et 14 jours après l'OACM chirurgicale. Les effets sur les changements des niveaux de p-NR2B, le poids corporel et le volume de l'infarctus cérébral étaient plus importants dans le groupe EFI que dans le groupe EIM. Discussion et conclusion : Ces observations démontrent que l'exercice physique peut avoir des effets neuroprotecteurs, en partie par la régulation à la baisse de l'expression du p-NR2B. De plus, l'intensité de l'exercice physique est un aspect crucial de la réadaptation après un AVC.

Can J Neurol Sci. 2012; 39: 613-618

With the growing aging population, strokes have become the second leading cause of mortality worldwide ${ }^{1}$, causing a huge financial burden on society, as well as on patients and their families. Rehabilitation is a routine and effective therapeutic strategy that is used in clinical practices for stroke patients. It can facilitate functional recovery by repairing damaged brain tissue and preventing post-stroke complications ${ }^{2,3}$. Some scholars believe that rehabilitation should begin as early as possible, once the patient's condition is stable ${ }^{4,5}$. Exercise training is one type of physical therapy commonly used after stroke. Matsuda et al and Yang et al reported that early treadmill training could significantly reduce brain infarct volume and improve neurologic function in rodent models of stroke $e^{6,7}$. Our previous studies also revealed that early exercise training ( 24 hours after stroke) tends to result in a better rehabilitative outcome in terms of brain infarct volume, compared to delayed exercise training (one week after stroke). However, the appropriate training intensity for stroke patients remains largely unknown. In clinical practice, training intensity is determined by the "step-by-step"

From the Department of Rehabilitation Medicine, Huashan Hospital, (AZ, YB, YH, FZ, YiW, QH), Department of Anatomy and Embryology (YaW), State Key Laboratory of Medical Neurobiology (PZ), Fudan University, Shanghai, China.

Received November 15, 2011. Final Revisions Submitted March 7, 2012. Correspondence to: Yulong Bai, Department of Rehabilitation Medicine, Huashan Hospital, Fudan University, Shanghai, 200040, China.

Email: doctorbaiyulong@126.com 
principle, which is largely affected by the experience of the physician or therapist. Excessive training can interfere with neurological recovery ${ }^{8}$ and even lead to stroke recurrence ${ }^{9}$. For example, too much constraint-induced movement in very early periods of recovery can impede the recovery progress of upper arm function ${ }^{10}$. On the other hand, insufficient training usually does not achieve the desired effect. Therefore, appropriate training intensity is essential for an effective and efficient poststroke recovery.

Glutamate N-Methyl-D-aspartic acid (NMDA) receptors are calcium-permeable ionotropic receptors that are comprised of several NMDA receptor subunits. One subunit, NR2B, is widely distributed in the hippocampus, cerebral cortex, and olfactory bulb. It plays an important role in the pathological processes of cerebral ischemia. When excessively activated by rapid increases in extracellular glutamate concentrations, NR2B can activate apoptotic signaling cascades and promote neuronal death ${ }^{11}$. Pre-ischemic treadmill training has been reported to down-regulate NR2B mRNA expression levels and induce brain ischemic tolerance ${ }^{12}$. Therefore, the purpose of the current study was to investigate whether the neuroprotective effects of physical exercise after cerebral ischemia were related to NR2B activities and, if so, to explore the relationship between training intensity and expression of the NR2B subunit. Our results demonstrate that treadmill training can indeed down-regulate phospho-NR2B (p-NR2B) levels but not change the expression of total NR2B. Furthermore, we found that, low-intensity training was more beneficial for the recovery of neurological function.

\section{Materials AND Methods}

\section{Animals and surgery procedures}

A total of 144 adult male Sprague-Dawley rats (250-300 g) were provided by Shanghai Laboratory Animal Center, Chinese Academy of Sciences. All experimental procedures were in accordance with the National Institute of Health Guide for the Care and Use of Laboratory Animals, and the ethical committee of Fudan University. All rats were housed under a 12 hour light/dark cycle and food and water were given ad libitum.

All animals were randomly divided into four groups $(n=36$ each), including sham, no exercise (NE), low intensity training (LIT, $\mathrm{v}=15 \mathrm{~m} / \mathrm{min}$ ), and moderate intensity training groups (MIT, $\mathrm{v}=20 \mathrm{~m} / \mathrm{min}$ ). For cerebral ischemic surgery, the rats were first anesthetized with $10 \%$ chloral hydrate $(330 \mathrm{mg} / \mathrm{kg})$ via intraperitoneal injection. The rats in the NE, LIT, and MIT groups had their left middle cerebral arteries occluded in perpetual according to the method described by Zea-Longa et $\mathrm{al}^{13}$. A filament with a poly-L-lysine coated blunted tip was inserted into the left common carotid artery via an incision. The filament was inserted into the internal carotid artery to the narrow proximal anterior cerebral artery. In order to occlude the middle cerebral artery at its orgin, the length of the filament inserted into the internal carotid artery was approximately 20 $\mathrm{mm}$. The rats in the sham group received the same operation but no vessel was occluded. Body temperature was maintained at $37^{\circ} \mathrm{C}$ by a heating pad.

\section{Neurological examination}

Twenty-four hours later, neurological status was examined using neurological defect scores, by a rater who was blind to the experimental designs ${ }^{14}$. Briefly, Grade 0 indicated no visible deficits; Grade 1 indicated contralateral forelimb flexion when the rat was held by its tail; Grade 2 indicated decreased grip of contralateral forelimb; Grade 3 indicated spontaneous movement in all directions but contralateral circling if the rat was held by its tail; Grade 4 indicated spontaneous contralateral circling; Grade 5 indicated death. Rats in Grades 2 to 4 were selected. On the $3 \mathrm{rd}, 7 \mathrm{th}$, and 14th day following middle cerebral artery occlusion (MCAO) surgery, neurological assessments were repeated.

\section{Treadmill exercise}

Prior to MCAO or sham surgery, all rats received three consecutive days of adaptive running exercise for 30 minutes (min) on an electrical treadmill machine (DSPT-202 Type 5Lane Treadmill, Litai Biotechnology, China). Electric shock was used to motivate the animals to continue running when the rats moved back onto the treadmill. Based on previous reports ${ }^{15,16}$, maximum exercise intensity was determined (at maximum exercise intensity, rats cannot run any longer because of fatigue within three minutes after the onset of exercise). The sham group and the NE group were then subjected to no exercise; LIT group was exercised at $40 \%$ of the maximum velocity; MIT group was exercised at $60 \%$ of the maximum velocity. Twenty-four hours after surgery, each rat in the LIT and MIT groups had a five min warmup at $5 \mathrm{~m} / \mathrm{min}$. Treadmill speed was then increased by 5 $\mathrm{m} / \mathrm{min}$ every five min until the target exercise intensity was reached. Treadmill training was at a slope of $0^{\circ}$ for $30 \mathrm{~min} /$ day until sacrifice.

\section{Infarct volume}

Infarct volume was measured as previously described ${ }^{17}$. Five rats in each group were anesthetized with chloral hydrate and decapitated quickly at each time point (3rd, 7th, and 14th day) after MCAO surgery. The brain was removed carefully and put into $-20^{\circ} \mathrm{C}$ for $30 \mathrm{~min}$, then sliced into $2.0 \mathrm{~mm}$-thick coronal sections with a mold and razor blades. Subsequently, the brain sections were incubated in $2 \%$ 2,3,5-triphenyltetrazolium chloride (TTC) solution for $30 \mathrm{~min}$ at $37^{\circ} \mathrm{C}$ and transferred into $4 \%$ paraformaldehyde solution for fixation. The infarction volumes were measured by a rater blind to the experimental designs using Image-pro plus 6.0 software. The method described by Swanson ${ }^{18}$ was used to minimize edema-related errors.

Data were expressed as follows:

Infarct volume $=$ contralateral hemisphere region - noninfarcted region in the ipsilateral hemisphere;

Infarct percentage $=$ infarct volume/volume of the contralateral hemisphere $\times 100 \%$.

\section{Protein extraction and Western blot analysis}

According to Watanabe et al, the expression of NR2B in the adult rat brain is the highest in the cortex, hippocampus, amygdala, ventral nuclei of the thalamus and olfactory bulb ${ }^{19}$. In 
order to ensure experimental accuracy, hippocampal tissues in the ischemic hemispheres of our rats were collected at different time points and homogenized on ice in superactive RARI lysis buffer (Beyotime Biotechnology, China). After incubation at $4^{\circ} \mathrm{C}$ for $30 \mathrm{~min}$, the homogenates were centrifuged at $14000 \mathrm{~g}$ at $4^{\circ} \mathrm{C}$ for $25 \mathrm{~min}$ and the supernatants were collected. Protein concentrations were measured with a BCA kit (Beyotime Biotechnology, China) and stored at $-80^{\circ} \mathrm{C}$ until use.

Western blot analysis was performed as previously described ${ }^{20}$. Briefly, proteins were separated on $8 \%$ SDS-PAGE gels and transferred onto polyvinylidene fluoride (PVDF) membranes. Membranes were incubated with p-NR2B (Tyr1472) primary antibodies (Cell Signaling Tech., Beverly, MA) and the total NR2B primary antibodies (Cell Signaling Tech., Beverly, MA). Glyceraldehyde 3-phosphate dehydrogenase (GAPDH) was used as a loading control. Proteins were visualized with an enhanced chemiluminescence kit (Pierce, Rockford, IL), and densitometry was performed using Quantity One software.

\section{StaTisTiCAL ANALYSIS}

Cerebral infarct volumes were presented as mean $\pm \mathrm{SE}, \mathrm{p}<$ 0.05 was considered statistically significant. The other data were presented as mean $\pm \mathrm{SD}$, $\mathrm{p}<0.05$ was considered statistically significant. Cerebral infarct volumes and neurological scores were analyzed by one-way analysis of variance (ANOVA), followed by Fisher's Least Significant Difference (LSD) post hoc test. Body weights collected at different time points were analyzed by repeated measures ANOVA, followed by Fisher's LSD post hoc test. Mortality was analyzed by log-rank test (Kaplan-Meier method). All statistical analyses were performed with SPSS 11.0 software program.

\section{Results}

\section{Mortality rate}

Six rats died within 24 hours after onset of stroke and were not included in the data analysis. During the experiment, 15 rats died spontaneously before the sampling time point and were

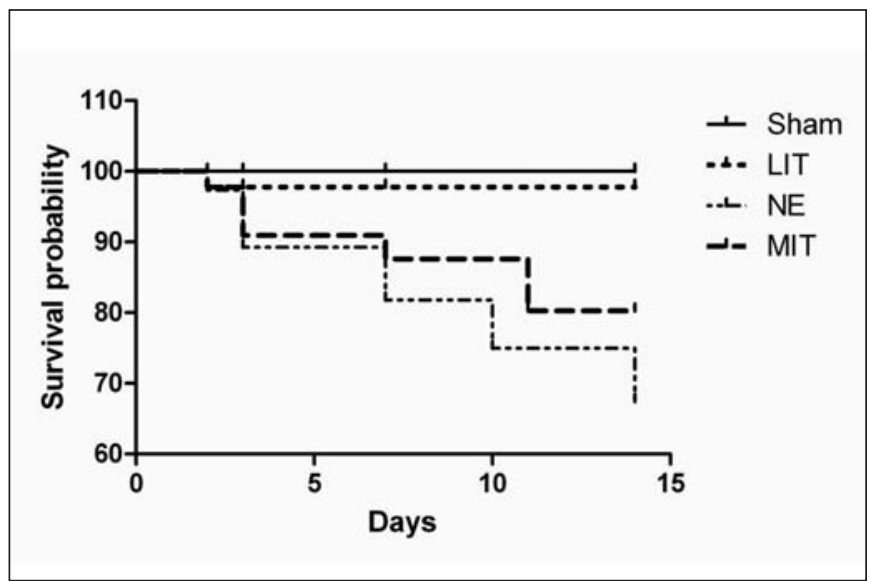

Figure 1: The mortality results of each group were presented as a Kaplan-Meier survival curve. The horizontal axis is the time after the $M C A O$ operation. The longitudinal axis is the survival probability. used for the mortality analysis. Mortality rates for each group were as follows: 0 in the sham group, 8 in the NE group, 1 in the LIT group, and 6 in the MIT group. No significant differences were found between the NE and MIT groups. However, the mortality rate in the LIT group was significantly lower than the MIT groups and the NE group ( $\mathrm{p}<0.05)$ (Figure 1).

\section{Body weight}

After surgery, all groups, including the sham group, suffered a short period of weight loss followed by weight gain (Figure 2). For the sham and LIT groups, body weight gain started before the 7th day following the operation; whereas for the NE and MIT groups, the duration of body weight loss was longer. There were no significant differences in baseline body weight among the four groups. On the $3 \mathrm{rd}$, 7th, and 14th days, the body weight of the sham group was significantly different from the other groups $(p<0.05)$. In addition, on the 7th day the body weight of the LIT group was heavier than the NE and MIT groups (LIT vs. NE: 194.33 grams $(\mathrm{g}) \pm 19.42$ vs. $162.33 \mathrm{~g} \pm 21.56, \mathrm{p}<0.05$; LIT vs. MIT: $194.33 \mathrm{~g} \pm 19.42$ vs. $176.67 \mathrm{~g} \pm 25.37, \mathrm{P}<0.05)$. On the 14 th day the trend was much marked (LIT vs. NE: $244.83 \mathrm{~g} \pm$ 11.26 vs. $162.00 \mathrm{~g} \pm 20.50, \mathrm{p}<0.01$; LIT vs. MIT: $244.83 \mathrm{~g} \pm$ 11.26 vs. $205.08 \mathrm{~g} \pm 30.43, \mathrm{p}<0.05)$. Finally, on the 14 th day, the body weight of MIT group was also significant heavier than the NE group (205.08 g \pm 30.43 vs. $162.00 \mathrm{~g} \pm 20.50, \mathrm{p}<0.01)$

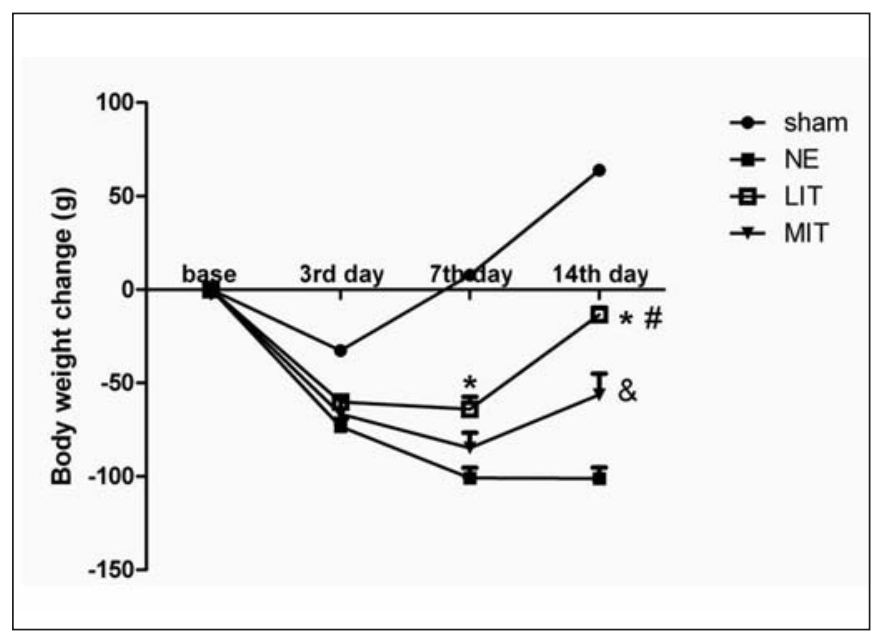

Figure 2: The change of rats body weight in 4 groups $(n=12)$ at each sampling time points. * the NE group vs. the LIT group $(p<0.05)$; \# the MIT group vs. the LIT group ( $p<0.05)$. \&: the NE group vs. the MIT group $(p<0.05)$.

\section{Neurological examination}

Rats in the sham group had no neurological impairment, so their scores were zero. The degree of cerebral ischemic impairment in the three MCAO-treated groups ( $\mathrm{n}=12$ each) were assessed at multiple time points after the operation (Figure 


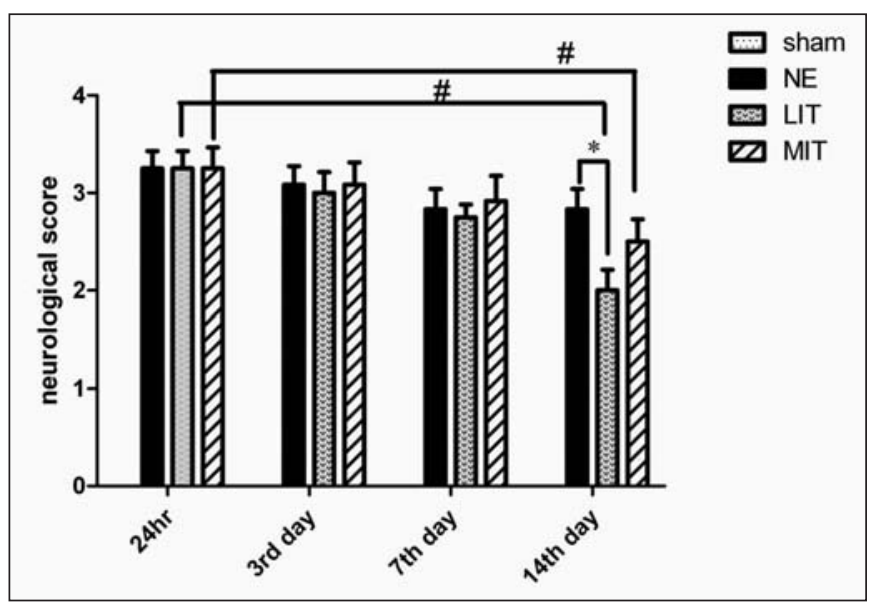

Figure 3: Neurological scores (mean $\pm S D$ ) at various time points after surgery $(n=12)$. The scores in the physical exercise group were significantly lower than the NE group on the 14th day after the MCAO operation. *: $p<0.05$ compared to the NE group. \#: $p<0.05$ compared to the same intervention group at $24 \mathrm{hr}$ after the MCAO surgery.

3). There were no evident differences between the three groups on the 1st, 3rd, and 7th day after ischemia. On the 14th day the scores of the two training groups were much lower than the NE group ( $<0.05$ ). The neurological scores in the LIT and MIT groups were comparable.

\section{Cerebral Infarct volume}

The sham group did not show any infarction. No significant differences were observed on the 3rd day following MCAO surgery among the three treatment groups. Infarction volumes in the LIT group were reduced by $60.2 \%$ on the 7 th day, and $82.9 \%$ on the 14th day, respectively. In stark contrast, infarct volumes in the MIT group were reduced by $33.8 \%$ on the 7 th day and $58.4 \%$ on the 14 th day, respectively. Infarct volume in the NE group was reduced by $11.4 \%$ on the 7 th day and $34.8 \%$ on the 14th day, respectively. Significant differences in the cerebral infarct volume were found between the training and NE groups $(p<0.01)$ (Figure 4). Significant differences were also observed on the 7th and 14th day between the LIT and MIT groups ( $p<$ 0.01 ). No significant reduction in infarct volumes was detected in the NE group on the 3rd or 7th day.

\section{Expressions of p-NR2B and total NR2B}

The Western blot data are summarized in Figure 5. Compared to the sham group, ischemic injury increased hippocampal expression levels of p-NR2B on the 3rd day in all three MACOtreated groups. On the 7th and 14th day, hippocampal levels of $\mathrm{p}-\mathrm{NR} 2 \mathrm{~B}$ were decreased in both the LIT and MIT groups ( $\mathrm{p}<$ 0.01 ). At each sampling time point, we found no change in the expression of total NR2B between groups.

\section{Discussion}

Physical training is an effective behavioral intervention strategy for preventing complications and aiding in recovery after stroke ${ }^{21}$. In the current study, in comparison to the no exercise group, rats in both treadmill exercise groups had improved neurological function and decreased the expression of p-NR2B protein levels after a two-week training period. This is consistent with a previous report by Lee et al showing that mild to moderate treadmill training starting $24 \mathrm{~h}$ after focal cerebral ischemia, markedly improves neurological function ${ }^{22}$.

However, training intensity largely determines treatment outcomes. Current findings indicate that a lower training intensity does lead to better therapeutic effects. Scopel et al reported that higher intensity training can exacerbate brain damage caused by ischemia, whereas the effects of moderate intensity training are encouraging ${ }^{15}$. Cell proliferation in the dentate gyrus of the rat hippocampus is also affected by the intensity of treadmill exercise, and is most prominent in the light-exercise group ${ }^{23}$. Some growth factors implicated in neuroplastic processes occur with prolonged expression and elevated results following lower intensity exercise ${ }^{24}$. Low intensity training can also increase muscle mass, dietary intake and body weight $t^{25}$, which may be accompanied by enhanced neurotrophin lervels.

Many studies have explored the effects of exercise intensity on functional recovery after stroke from the perspective of clinical studies ${ }^{6}$, animal models ${ }^{26}$ and cellular and molecular work on proteins involved in the post-ischemic pathophysiological processes of cerebral metabolism ${ }^{27,28}$. Among these, excitotoxic neuronal damage caused by overactivation of NR2B subunits is thought to be a principal cause of neuronal loss after stroke. For NR2B subunits, tyrosine phosphorylation has emerged as a prominent mechanism for regulating the function and number of receptors ${ }^{29}$. The regulation of NMDARs by tyrosine phosphorylation is members of the Src family of protein tyrosine kinases (PTKs), which induce phosphorylationdependent upregulation of NMDAR function ${ }^{30}$.

Interestingly, it has been shown that NR2B receptor expression can be regulated by physical exercise ${ }^{12,31}$. When normal mice receive exercise for one month, the overall content of NR2B subunits were not altered. However, p-NR2B increased by $83 \%{ }^{32}$. Changes in the NR2B subunit in the training process after ischemia are still poorly understood.

Previous studies have revealed that underwent one month exercise before cerebral ischemia, relative mGluR5 and NR2B gene expression levels in rats of the training group are significantly decreased compared to those in the no exercise group $^{12}$. Whether ischemia tolerance is mediated by the decreased gene expression of NR2B is still unknown. Because NMDA receptor function can also be modulated by neighboring activated receptors, including mGluRs ${ }^{33}$. In the present study, we focused on the functions of NR2B subunits, and found a decrease in p-NR2B levels in both treadmill exercise groups, particularly in the LIT group but no changes of total NR2B levels between groups at any sampling time points. We also observed that LIT contributed to body weight growth after the initial weight loss, and changes in body weight paralleled the recovering neurological function of the ischemic rats. Improved motor capacity and recovery of the nerve system allows the rats to eat more easily and thus regain body weight. This correlated with diminished neurological symptoms and greater decrease in cerebral infarct volume. 


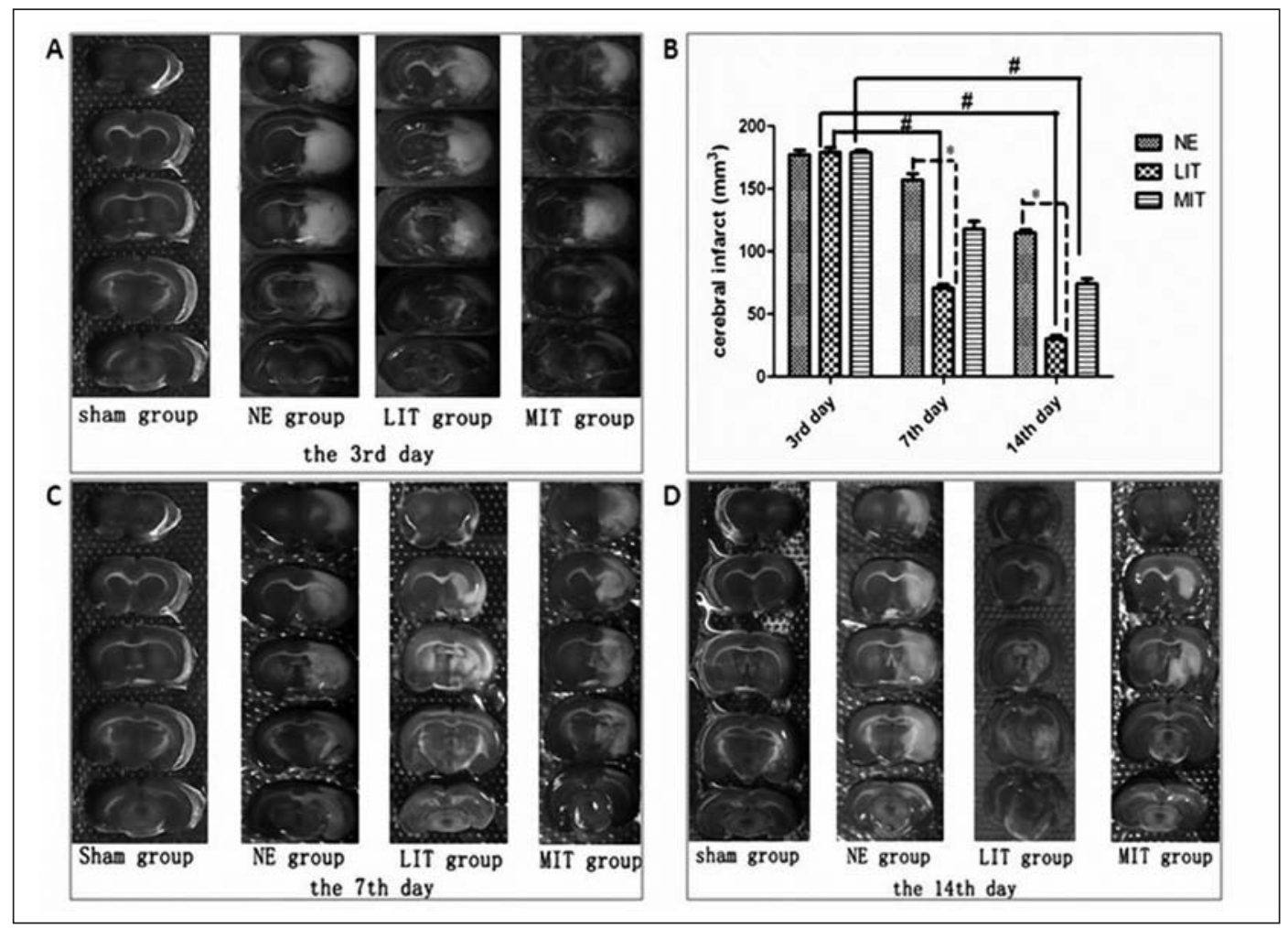

Figure 4: Brain infarction revealed by TTC staining at various time points after surgery. A: On the third day, original TTC image of brain infarction of every group after middle cerebral artery occlusion; $C$ and D: TTC image on the 7th day and 14th day. In normal cells, TTC reacts with dehydrogenases and results in brick-red color; the white area indicates the ischemia. A, C, D indicate that ipsilateral cerebral tissue was affected by MCAO. B: the quantification of infract area in four groups on the third, seventh and fourteenth days after MACO.*: compared to the NE group at the same sample time $(P<0.05)$; \#: compared to the same intervention group on the 3rd day $(P<0.05)$.

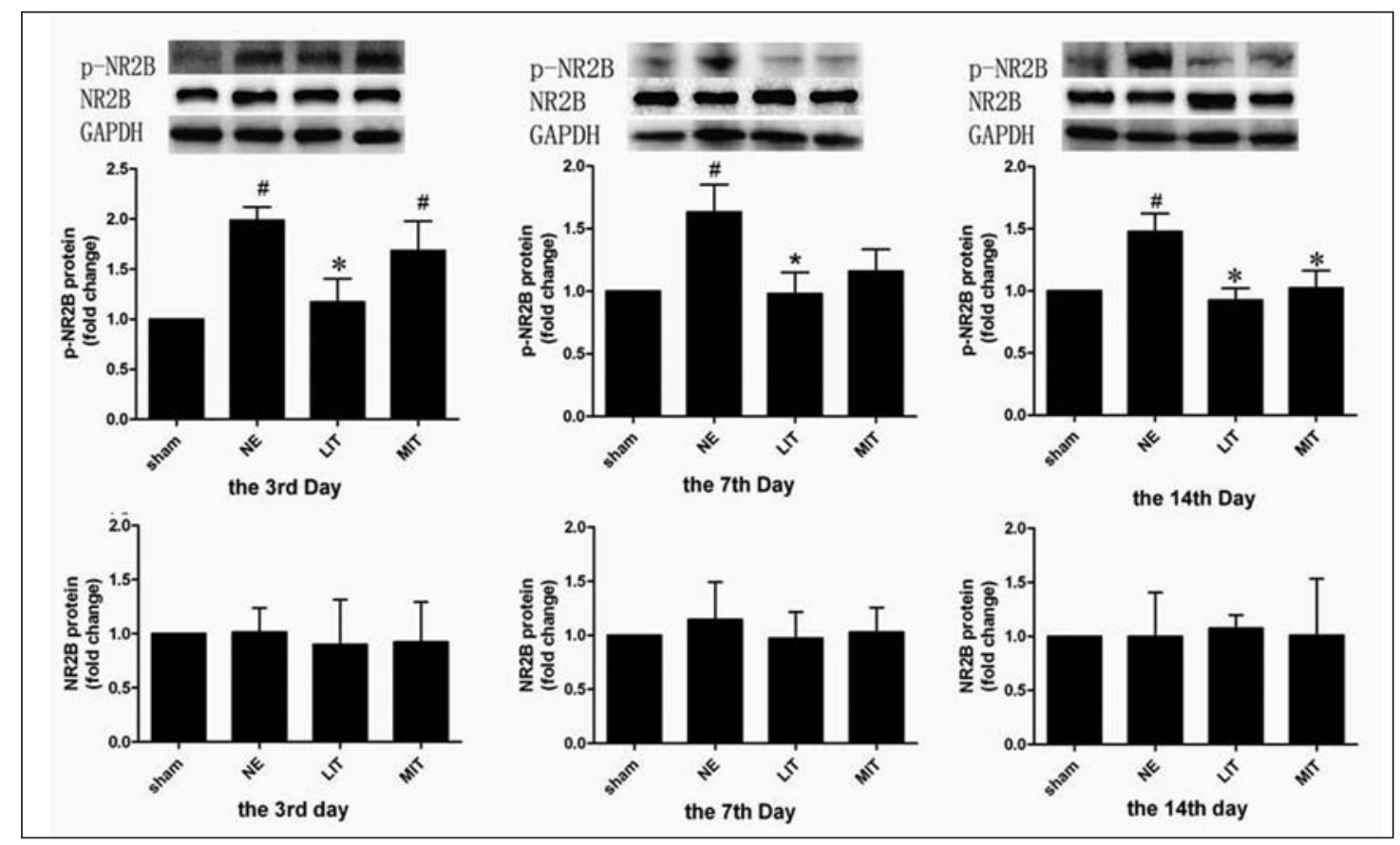

Figure 5: Western blot analysis of hippocampal phospho-NR2B and total NR2B expression $(n=3)$. The top figures are representative Western blots showing phospho-NR2B and total NR2B expression in the rats (sham, NE, LIT, and MIT groups). In all bar charts the relative phosphoprotein level are expressed as percentage of the sham group, and normalized to GAPDH band respectively. In all experiments levels of total NR2B remained unchanged. $* P<0.05$ compared to the NE group; \#: $P<0.05$ compared to the sham group. 
Intense exercise for a short period may be stressful to the ischemic brain; however, low intensity exercise may result in adaptation and attenuation of the stress response ${ }^{24}$. Naylor et al also found that long term restricted running could reduce the expression of corticosterone and reverse the deleterious effects on neurogenesis ${ }^{34}$.

Since NR2B subunits are reduced by low training intensity post-ischemia, overall it is very possible that low intensity exercise in beneficial. Nevertheless, it may be of importance to use graduated exercise protocols to alleviate any harmful stress response.

\section{ConCLusion}

In summary, the present findings demonstrate that physical exercise can produce neuroprotective effects in part by downregulating the activity of NR2B. The appropriate intensity level of physical exercise is critical for post-stroke rehabilitation.

\section{ACKNOWLEDGEMENTS}

This study was supported by the National Natural Science Foundation of China (No.30772300) and the 863 Development Program of China (No.2007AA02Z482).

The authors thank Medjaden Bioscience Limited for assisting in the preparation of this manuscript.

\section{REFERENCES}

1. Lopez AD, Mathers CD, Ezzati M, et al. Global and regional burden of disease and risk factors, 2001: systematic analysis of population health data. Lancet. 2006;367(9524):1747-57.

2. Nudo RJ, Wise BM, SiFuentes F, et al. Neural substrates for the effects of rehabilitative training on motor recovery after ischemic infarct. Science. 1996;272(5269):1791-4.

3. Dombovy ML, Sandok BA, Basford JR. Rehabilitation for stroke: a review. Stroke. 1986;17(3):363-9.

4. Kim DE, Park JW, Bang MS, et al. Early treadmill training promotes motor function after hemorrhagic stroke in rats. Neurosci Lett. 2010;471(2):104-8.

5. Bernhardt J, Cumming TB, Thrift AG, et al. Very early mobilization after stroke fast-tracks return to walking further results from the phase II AVERT randomized controlled trial. Stroke. 2011;42(1): 153-8.

6. Matsuda F, Sakakima H, Yoshida Y. The effects of early exercise on brain damage and recovery after focal cerebral infarction in rats. Acta Physiol (Oxf). 2011;201(2):275-87.

7. Yang YR, Wang RY, Wang PSG. Early and late treadmill training after focal brain ischemia in rats. Neurosci Lett. 2003;339(2): 91-4.

8. Cramer SC. The VECTORS study: when too much of a good thing is harmful. Neurology. 2009;73(3):170-1.

9. Risedal A, Zeng JS, Johansson BB. Early training may exacerbate brain damage after focal brain ischemia in the rat. J Cereb Blood Flow Metab. 1999;19(9):997-1003.

10. Dromerick AW, Lang CE, Birkenmeier RL, et al. Very early constraint-induced movement during stroke rehabilitation (VECTORS): a single-center RCT. Neurology. 2009;73(3): 195-201.

11. Liu YT, Wong TP, Aarts M, et al. NMDA receptor subunits have differential roles in mediating excitotoxic neuronal death both in vitro and in vivo. J Neurosci. 2007;27(11):2846-57.

12. Zhang F, Jia J, Wu Y, et al. The Effect of Treadmill Training PreExercise on Glutamate Receptor Expression in Rats after Cerebral Ischemia. Int J Mol Sci. 2010;11(7):2658-69.

13. Longa EZ, Weinstein PR, Carlson S, et al. Reversible middle cerebral-artery occlusion without craniectomy in rats. Stroke. 1989;20(1):84-91.
14. Maddahi A, Chen QW, Edvinsson L. Enhanced cerebrovascular expression of matrix metalloproteinase- 9 and tissue inhibitor of metalloproteinase-1 via the MEK/ERK pathway during cerebral ischemia in the rat. BMC Neurosci. 2009;10:56.

15. Scopel D, Fochesatto C, Cimarosti H, et al. Exercise intensity influences cell injury in rat hippocampal slices exposed to oxygen and glucose deprivation. Brain Res Bull. 2006;71(1-3): $155-9$.

16. Wisloff U, Helgerud $\mathrm{J}$, Kemi OJ, et al. Intensity-controlled treadmill running in rats: $\mathrm{VO}(2$ max $)$ and cardiac hypertrophy. Am J Physiol Heart Circ Physiol. 2001;280(3):H1301-10.

17. Shimamura N, Matchett G, Tsubokawa T, et al. Comparison of silicon-coated nylon suture to plain nylon suture in the rat middle cerebral artery occlusion model. J Neurosci Methods. 2006;156(1-2):161-5.

18. Swanson RA, Morton MT, Tsaowu G, et al. A semiautomated method for measuring brain infarct volume. J Cereb Blood Flow Metab. 1990;10(2):290-3.

19. Watanabe M, Inoue Y, Sakimura K, et al. Distinct spatio-temporal distributions of the NMDA receptor channel subunit mRNAs in the brain. Ann N Y Acad Sci. 1993;707:463-6.

20. Krebs B, Kohlmannsperger V, Nolting S, et al. A method to perform Western blots of microscopic areas of histological sections. J Histochem Cytochem. 2006;54(5):559-65.

21. Zhang F, Wu Y, Jia J, et al. Pre-Ischemic Treadmill training induces tolerance to brain ischemia: involvement of glutamate and ERK1/2. Molecules. 2010;15(8):5246-57.

22. Lee SU, Kim DY, Park SH, et al. Mild to moderate early exercise promotes recovery from cerebral ischemia in rats. Can J Neurol Sci. 2009;36(4):443-9.

23. Kim YP, Kim HB, Jang MH, et al. Magnitude- and timedependence of the effect of treadmill exercise on cell proliferation in the dentate gyrus of rats. Int J Sports Med. 2003; 24(2):114-7.

24. Ploughman M, Granter-Button S, Chernenko G, et al. Exercise intensity influences the temporal profile of growth factors involved in neuronal plasticity following focal ischemia. Brain Res. 2007;1150:207-16.

25. Choe MA, An GJ, Lee YK, et al. Effect of early low-intensity exercise on rat hind-limb muscles following acute ischemic stroke. Biol Res Nurs. 2006;7(3):163-74.

26. Ke Z, Yip SP, Li L, et al. The effects of voluntary, involuntary, and forced exercises on brain-derived neurotrophic factor and motor function recovery: a rat brain ischemia model. PLoS One. 2011; 6(2): 16643.

27. Kinni H, Guo M, Ding JY, et al. Cerebral metabolism after forced or voluntary physical exercise. Brain Res. 2011;1388:48-55.

28. Hayes K, Sprague S, Guo M, et al. Forced, not voluntary, exercise effectively induces neuroprotection in stroke. Acta Neuropathol. 2008;115(3):289-96.

29. Salter MW, Kalia LV. Src kinases: a hub for NMDA receptor regulation. Nat Rev Neurosci. 2004;5(4):317-28.

30. Groveman BR, Feng S, Fang XQ, et al. The regulation of Nmethyl-D-aspartate receptors by Src kinase. FEBS J. 2012;279(1):20-8.

31. Vasuta C, Caunt C, James R, et al. Effects of exercise on NMDA receptor subunit contributions to bidirectional synaptic plasticity in the mouse dentate gyrus. Hippocampus. 2007;17(12):1201-8.

32. Dietrich MO, Mantese CE, Porciuncula LO, et al. Exercise affects glutamate receptors in postsynaptic densities from cortical mice brain. Brain Res. 2005;1065(1-2):20-5.

33. Guo W, Wei F, Zou S, et al. Group I metabotropic glutamate receptor NMDA receptor coupling and signaling cascade mediate spinal dorsal horn NMDA receptor 2B tyrosine phosphorylation associated with inflammatory hyperalgesia. J Neurosci. 2004;24(41):9161-73.

34. Naylor AS, Persson AI, Eriksson PS, et al. Extended voluntary running inhibits exercise-induced adult hippocampal progenitor proliferation in the spontaneously hypertensive rat. $\mathrm{J}$ Neurophysiol. 2005;93(5):2406-14. 